\title{
A Product Pain-Pleasure Framework for Software Product Design in the Usability and User Experience Domains
}

\author{
Wahidah Hashim \\ Institute of Informatics and Computing in Energy, Universiti Tenaga Nasional, Kajang, Malaysia. \\ E-mail:wahidah@uniten.edu.my
}

Emmanuel O.C. Mkpojiogu

School of Computing, Universiti Utara Malaysia, UUM, Sintok, Malaysia and Department of Computer and Information Technology, Veritas University, Abuja, Nigeria.

\author{
Azham Hussain \\ School of Computing, Universiti Utara Malaysia, UUM, Sintok, Malaysia.
}

Shahrun Nizam Abdul-Aziz

Universiti Pendidikan Sultan Idris, Tanjong Malim, Perak, Malaysia.

Received October 04, 2020; Accepted November 15, 2020

ISSN: $1735-188 X$

DOI: $10.14704 / W E B / V 18 S I 01 / W E B 18004$

\begin{abstract}
This study utilized a literature review strategy to examine prior literature pertaining to the frameworks concerning how to minimize users' pain and maximize their pleasure while interacting with the designs of interactive products. The findings of the study reveal that several such frameworks are in existence and are mainly in other domains different from usability and user experience. In these, the emphasis were mostly on satisfaction and dissatisfaction criteria which do not cover the broader perspectives of user experience that comprise hedonic, affective, aesthetics and other hedonomic facets. This prompts for the development of a framework that tailored to usability and user experience concerns to enable user experience designers design interactive products that will enhance users' experience. The proposed framework was adapted from previous related frameworks It is a three-factor framework that is composed of pain factors, linear factors and pleasure factors. The study proposes this framework to facilitate the design of interactive systems that improves the experience of users.
\end{abstract}

\section{Keywords}

Design, Evaluation, Framework, Pain, Pleasure, Product, Software, User Experience. 


\section{Introduction}

Interactive systems are defined by the International Standard Organization, ISO 9241-210 (2010) in Samardžija (2016) as the "combination of hardware, software and/or services that receives input from, and communicates output to users". Interactive systems are generally systems that receive input from users and deliver information as output to them. Benyon (2010) in Samardžija (2016), in addition, utilized the term 'interactive systems' to describe the elements, devices, components, products and software applications and systems that deal with the reception, transmission, display, storage or transformation of information which users can perceive, understand, and that can respond interactively or dynamically to users' actions. Interactive systems are thus, systems that enable interaction between users and the system in use. In addition, interactive systems can be looked at from both the system and user perspectives. To users, an interactive system is a tool for accomplishing tasks, carrying out goals, it is something that receives input from them, and as well displays/delivers output to them too (Samardžija, 2016). However, to the interactive system, the user is a source of asynchronous input, an indirect target for output via various devices (like speakers, display units, lights, etc.) (Samardžija, 2016). Notably, interactive systems involve an important degree of user interaction. Physically, users interact with systems via some media of interaction like mouse, keyboard, video input, voice recognition, camaras, touch screen, joy sticks, and motion sensors, among others. There are systems that employ several ways of communication with the system (that is, modalities of interaction-haptic, verbal, and/or visual). These systems are known in literature as multimodal systems. According to Roberto (2013), interactive systems have become an emergent reality universally and users utilize them using "different devices, for different purposes, in quite different contexts, and with unforeseen and far-reaching consequences" (Roberto, 2013). Interactive systems has profoundly transformed the way people work and play, and has become an essential part of people's daily life and activities (Samardžija, 2016).

User experience (UX) is described as "a person's perceptions and responses that result from the use or anticipated use of a product, system or service" (ISO 9241-210, 2010 in Samardžija, 2016). This definition is a promising one as it is consistent with the view of majority of the researchers on the subjectivity of UX. However the terms used require that more clarifications be made on the list of possible objects that influence UX. UX a tightly coupled with and associated to usability (Law et al., 2009). Usability has various qualities such as efficiency, effectiveness and satisfaction. Satisfaction quality relates to the likeliness, pleasure, trust and other similar characteristics, and from this standpoint, UX is taken to be as elaboration of usability. Usability is different from UX because it focuses 
on objective measures, while UX focuses on subjective measures. This dissimilarity is hinged on the use of measurement methods. Usability methods are not likely to measure UX because there is a distinct dissimilarity between usability qualities and those of UX. UX is a canopy term for users' perceptions, whether measured objectively or subjectively and it follows the ISO 9241-210 definition which encompasses perceptions from the user whether objectively or subjectively measured (Alharbi, 2016).

In addition, Hekkert (2006) in Hart (2014) considered some concepts related to UX: Product experience, with a perspective focusing on affects or emotions, entails a whole set/collection of affects that is generated through the interaction between a user and a specified product. Product experience can be viewed as having to some extent a more narrower scope and delimitation than UX, since not all interactive or technological artifacts are products per se. Brand experience, however does not only comprise interaction with the branded products, none the less, it also includes interaction with the company, and other services and products belonging to the company. This therefore makes brand experience a some what wider concept than UX (Law et al., 2009). Besides, the term service experience also exists, never the less it needs to be used cautiously, since it can, in an extensive sense, relate to face-to-face services (for example, in a cafeteria, or over the counter service in say, banks), public services (for example, public works infrastructural services), along with digital/online services on the Internet (for example, online stores) or any such related thing. In clarifying these variances, Law et al. (2009) contend that the experiences of, for instance, brands, events, exercises, spaces, arts, or face-to-face interaction are not part, that is, do not have their place under the canopy of UX. Generally, even though the concept of UX is still relatively young and evolving, there are a few basic assumptions that are common and widely accepted (Law et al. 2009). Law et al. (2009) conducted a survey with 275 researchers and professionals in UX to elicit views about UX and to comprehend its scope. Their study concluded that UX is: i) Subjective: an aroused experience that its characteristic features and valences vary individually, from person to person, even though the system, activity, and usage contexts maybe similar (i.e., the same); ii) Context-dependent: the same interaction may create varying experiences under varying social, physical, and cultural environments or situations; and iii) Dynamic: the overall user experience is cumulative and evolves with time.

Earlier research in UX contended that the concepts or notions of usability were narrowly too concentrated on task success, performance, efficiency-in-use, effectiveness, productivity, cost-in-use and learnability-in-use, etc. This inevitably made a notion of quality that is wider in focus to be thenceforth required (Hart, 2014). The issues and 
challenges with usability was its over concentration on the ergonomic, instrumental, performance, utilitarian, pragmatic and functional aspects of a product (Hart, 2014). Gaver and Martin (2000) in Hart (2014) however contended for a broader collection of substitutive lists of needs in which to assessand appraise digital technologies and application interfaces. Shackel and Richardson (1991) posits that the usability of an interactive digital artifact or application "is the capability [of a product] in human functional terms to be used easily and effectively by the specified range of users, given specified training and user support, to fulfill the specified range of tasks, within the specified range of environmental scenarios". From this definition it can be adjudged that usability is an essential and pivotal concept in human-computer interaction (HCI) as has been argued on by scholars for some decades (Hart, 2014). Scholarly arguments have been with respect to the definition, scope and use of usability as a measuring parameter (Dillon \& Watson, 1996 in Hart, 2014). Usability emerged initially in the 1980s as a replacement for the term 'user friendly'. By it, designers were compelled to be more usercentered in their design approach and to give attention to and place consideration on users all through the design phases and activities. This turned around to become a turning point in the design of computer systems, which hither to traditionally concentrated on a design approach that is top-down, where all user requirements were itemized in the product planning phase (Hart, 2014). The concept of usability has progressed evolutionally along several stages of definitions, with early expressions of 'ease of use', that was characterized by Eason in 1984, who used 4 constituents: 1) user characteristics, 2) task characteristics, 3) system functionality and 4) the usage environment. Furthermore, Shackel and Richardson (1991) later expanded it and included 4more operational aspects (including: effectiveness, flexibility, learnability, and attitude) to assist in the assessment of usability at the time of use. This opened the door for the Nielsen's (1993) assessment methods that consisted of several quantifiable characteristics (for example, memorability, learnability, errors, efficiency and satisfaction). Moreover, the International Organization for Standardization provided its first formal definition for usability in her ISO 9241-11 standard of 1998, and defines usability as, "the extent to which a product can be used by specified users to achieve specified goals with effectiveness, efficiency and satisfaction in a specified context of use". The conciseness, coverage and veracity of this definition underscores its popular usage. The definition of usability emphasized its measurable facets (that includes:efficiency, effectiveness, and satisfaction) that are assessed with respect to context-of-use (that is, in terms of the user, task, time, location, users' disposition and situation) (Hart, 2014). 
In addition, the ISO/IEC 25010(2011) in Hart (2014) Quality-in-use standard stipulates usability is one of the software quality metrics. The standard defines usability as the extent to which a software system can be used by users to cater for their needs. It covers effectiveness, efficiency, satisfaction, freedom from risk, and context coverage. As asserted by the ISO/IEC 25010 (2011) standard, the following attributes are included in the usability quality: i) effectiveness in use: this is the degree to which users achieve specified goalsin a specified usage context; ii) efficiency of use: this is the extent to which users utilize suitable and minimum amount of resources in achieving their goals in a given context of use; iii) freedom from risk: this is the extent to which possible or potential risks are prevented in the design of an interface to save human life, avert users from harm, promote users' health and protect their environment as they use a particular product. Any possibility of the occurrence of bad events can be termed a risk. A good product is expected to make provision for the mitigation of risks; iv) context coverage: this is the extent to which a product can be used to achieve results successfully with minimal errors and resources and with freedom from risk in a specified usage context. Context explains the situation or environment at/in which a user uses a product, that is, it is the environment or situation of use; and v) satisfaction in use: this refers to the extent to which users are comfortable with a product they used in a specified usage context.

While effectiveness and efficiency as objective or instrumental measures of usability are more easily measured, on the other hand, satisfaction, a subjective or perceptive measure of usability, is more difficult to measure, because it is highly perceptive in nature (Hart, 2014). Effectiveness denotes the completeness and accuracy with which users accomplish their specifictasks/goals and it is particularly measured using task completion (or success) rates, and error rates in a specified task. On the other hand, efficiency refers to the completeness and accuracy with which users successfully accomplish/complete their target tasks on an interface with minimal amount of resources expended in a given context of use. It has to do with the amount of resources expended by users to successfully achieve their goals. This attribute is measured using learning and task completion time and effort. Mean while, satisfaction is associated with the users' freedom from pain and discomfort and their positive behaviors/attitudes, likability, and feelings with respect to the use of a particular interactive digital application (Hart, 2014). It is measured using psychometric scales that evaluate users'overall subjective penchant, and their general acuities for the application's quality. These three measures or attributes of usability (effectiveness-in-use, efficiency-in-use, and satisfaction-of-use) are however assumed to strongly correlate. Nielson and Levy (1994) in Hart (2014) carried out a meta-analysis of fifty-seven studies in which they discovered that a strong correlation exists between the 
mean subjective satisfaction and mean task performance of users. Conversely these outcomes have lately been questioned by some other succeeding research studies that followed later (Hornbæk \& Law, 2007 in Hart, 2014). The studies submit that in usability assessment,objective performance measures are different from subjective perceptions, and that these subjective perceptions and performance measures can be dependent on users' prior preferences and computer-related experiences. Although usability quality was improved in the ISO 9126 (2001) in Hart (2014) standard to comprise more two (2) features (security and learnability), nonetheless, these ISO standards: ISO 9126 and ISO 9241-11, lacked concord, because they emanated from two different standpoints and fields (for instance, ISO 9241-11 emanated from the HCI field, where as ISO 9126 originated from the software engineering domain), thus making it a challenge for the two ISO Standards to be harmoniously interpreted and applied.

Following the in consistency in standards for usability, the evaluation of usability has proven to be a challenge. This not with standing, there are various practical approaches to the evaluation of usability that have been proposed in literature, these include: GOMs, heuristic evaluation (Nielsen, 1994), user testing methods and cognitive walk throughs. These methods presume that there is the possibility of identifying usability at different granular levels. In addition, Nielsen (1993) provided a broad array of design heuristics or principles that can be carried out by small groups of (say, three to five) evaluators to ascertain the usability quality of websites (Nielsen, 1994). As Nielsen (1993) posits, usability consists of 5 qualities (that is, memorability, learnability, errors, efficiency, and satisfaction). He claimed that these attributes can offer valued diagnostic assistance to industrial practitioners to enhance usability quality. Though these approaches are beneficial in confirming that products are more usable, they however, were discovered to be limited in the assessment of the subjective aspects (such as, aesthetics, affectivity, playfulness, and attractiveness, etc.) of interactive products, and in the evaluation of how these impact on the emotional experiences of users as they use the interactive systems. Consequently, it is thenceforth necessary that a broad based prospective was needed, that will extend the concept of the traditional usability to adequately capture UX.

There are several critiques on the traditional usability approach that lay emphasis on the objective characteristics of effectiveness, learnability and efficiency and that concentrate on the assessable facets of task success, performance, cost-in-use, and productivity. This approach which is also based on laboratory testing and experiments however missed out on the perceptive and subjective context of HCI. Carroll and Campbell's (1989) in Hart (2014) view on context of use, that artifacts really cannot be understood except from the within the situation and environment in which they are used, encouraged and prompted 
studies for the consideration of a broader context that goes beyond or transcends the traditional usability approaches (Hart, 2014). Furthermore, Carroll and Thomas (1988), threw a timely challenge for the separation of 'ease of use' and the motivational and affective characteristic of 'fun', contending that the notion of ease of use infers simplicity (that is, effortlessness), which is not essentially inclinable to stimulating a thing to be fun, therefore there is the likelihood that the thing could turn out to be uninteresting and boring. Thus, Carroll and Thomas (1988) noted that fun experiences are more attractive to users, and therefore called for a systematic research of fun (Carroll \& Thomas, 1988). Equally, Malone (1981) also noted the expressive variances observed among users who play educational games in relation to those who use computer as a tool for performing practical tasks, and then developed some set of principles or heuristics for intrinsic (implicit) motivation.

In addition, other facets of human-related behavior derived from research on consumer behavior specified and located emotional, affective and hedonic experiences as dominant motivators for the use of products. Similarly, research in design and ergonomics on the other hand recognized that usability did not take into account the positive feelings of "pleasure in product use" which leads to "emotional and hedonic benefits", that transcends usability (Jordan, 1998 in Hart, 2014). There have been a growing interest and popularity of affect in the design domain, as there has been for the motivational characteristics of fun, amusement, happiness, pleasure and enjoyment (Hart, 2014). Even though the notion of affect encapsulates a range of psychological and emotive states that comprised moods, emotions, passions and feelings etc., the terms affect, mood and emotion are interchangeably used frequently. Affect is frequently seen as representing or encapsulating both emotion and mood, where as emotion is usually a behavioral reaction or response that has a precise inducement (that is stimulus such as, person, object or event) that precede it, and is typically brief in its time of occurrence (seconds or minutes) (Hart, 2014). Mood is on the other hand is a more subtle, and non-specific condition that last longer and is less intense. It gives a person an inclination to positive or negative tendencies (Norman, 2002). Furthermore, affect can be observed as 'feelings' that are apparent in both mood and emotion states. As Russell (2003) maintained, 'Core Affect' is seen as a neurophysiological state that integrally blends the dimensions ofactivation value (such as, calm-excited) and hedonic valence (such as, pleasure-displeasure). Core affects are free flowing and are usually experienced in association to no known stimulus. Nonetheless the emotional quality of a stimulus (be it an object, place, or event) has the capability to modification or transform a user's core affect (that is, affective judgment or 'affect infusion') (Forgas, 1995 in Hart, 2014). 
Affective responses to a product has become one of the main emphasis in HCI. This was mirrored on in the revolutionary paradigm of 'Affective Computing' that drives at supporting naturalness in computing and enable computers to naturally interact with human needs, and possessing the aptitude to recognize, express and respond to emotions. In addition, studies have contended that humans do react to 'computers as social actors'and this signifies that users react to computers in the manner they do with or to other people in a natural context, in their use of interactive technology. The development of expressive graphics, icons and dynamic multi-media systems that utilized varying visual design features like color, light, sound, music, etc., led to the enhancement of the emotional experiences of users and also opened up a new avenue of research. Affective computing offered insight into the comprehension of phenomena such as attention, perception, memory and aesthetics, and show cased the significance of emotions and affects in association to human sense of judgement, decision-making and thinking processes. While affect within the UX domain signifies a user's prime subjective reaction to an interactive product, which may fluctuate and differ among various users, perceived ease-of-use or perceived usefulness is a user's cognitive reaction to an interactive digital product (Hart, 2014). This agrees and is in harmony with Norman (2002), who proposes that emotions, affects and cognitions interact with one another and impact on users' thought and value judgments. He further posits thata product's attractiveness and beauty can occasion a positive affective reaction and response from users, and that this can results in pleasure, and which can impacton a users' perception of the usability quality of a product. This led to his assertion as opined by Norman (2002) that "attractive things work better". The users' evaluative responses to the affectdrivers of a product,with regard to the product beauty or aesthetics and their likely impact on users' perception usability is thus a vital area to research in UX.

Positive affect is observed and revealed to have several positive impacts on users' cognition, for instance in aiding effective users' judgments and decision-making. Sheldon et al.'s (2001) study indicated a distinct connection between and positive affect in life events and the fulfillment of users' needs. Related works by Hassenzahl et al. (2010) in Hart (2014) indicated that these findings were can be generalized include users' positive experience with technological artifacts, as need fulfillment (relatedness) was distinctly connected to perceived hedonic qualities and positive affective experiences with interactive technology. Partala and Kallinen (2012) extended these studies by evaluating negative affective experience to offer insightful understanding into the users' needs and affective/emotional experiences that are most vital in both negative and positive experiential states. All the afore mentioned works utilized Watson et al.'s (1988) in Hart 
(2014) PANAS (Positive and Negative Affect Scale) that incorporates a set of items that evaluates ten positive, and ten negative affective attributes. Nevertheless, the study of Partala and Kallinen (2012) also elicited and captured qualitative data and suggests that there is more to learn from the content and context of narratives as expressed in the qualitative reflections on users' personal experiences with a product (Hart, 2014).

In addition, Porteous (1996) in Hart (2014) commenting on aesthetics posits that aesthetics is lucidly of great significance to the human sense of wellness and well-being. The significance of aesthetics is not actually new, though it was originally given low import and priority in HCI-related studies as a result of the difficulties in eliciting and evaluating as well as the challenges in gaining insight into the subjective perception of aesthetic value. None the less, the significance of routine aesthetics was supported and boosted in Dion and Bersheild's (1972) in Hart (2014) influential paper that investigated the psychological stereotype 'what is beautiful is good'and which showed that a person's physical appearance can have effect on his/her social interaction. It is also perceived that people that are more attractive are more intelligent, and such people have more successful jobs, and lead social lives that are happier. This is usually denoted as Meiners and Sheposh (1977) puts it as the 'halo effect'. This concept was also employed in product designs, in which case, the products' visual attractiveness is driven by its aesthetic qualities; implying that, the more beautiful or attractive a product is, the more it may be appealing to its users/consumers. Therefore, aesthetic design becomes vital in the design and development of new products, and has formed a huge part of strategies in retail marketing, employed to attain and reach acutting-edge competitive advantage that is very strategic to a business as the design of a product is an undisputed driver of its market performance, penetration and success. Even though the HCI community was some what slow in taking up and accepting how significant aesthetics is, it shortly turn out to be manifest that the design of certain interactive products (for example, Apple Computers), and the improved design of website offered a competitive edge, and became a vital part in the fashioning and framing of users attitudes towards the purchase and use of these products. Kurosu and Kashimura (1995) is one of such studies that noted that products should first be appealing (apparently usable) and also inherently usable. They discovered that users' aesthetic judgment strongly related to usability. Tractinsky (1997) replicated this study and sparked a debate concerning the relative effects of usability and aesthetics.

Interestingly, aesthetics is now one of the most commonly researched aspects in the domain of HCI (Bargas-Avila \& Hornbæk, 2011 in Hart, 2014). There are much differing perspectives on its relative effects on usability perceptions. Following the halo effect, a number of researches affirmed the association between the perception of aesthetics of an 
interactive interface and its usability perceptions. Tractinsky et al. (2000) in Hart (2014) discovered in a before and after experiment where users rated the changing layout of nine different ATM interfaces, that aesthetic perceptions were highly correlated to usability perceptions, and this resulted in the postulation that 'what is beautiful is usable'. Comparable associations were revealed by Lavie and Tractinsky (2004) in Hart (2014) who presented a multi-dimensional model of usability and aesthetics, which was later extended by Tractinsky and Zmiri (2006) in Hart (2014) to comprise symbolism as an added quality dimension. Additional experimental research studies buttressed Tractinsky's (1997) postulations, indicating that aesthetic designs impacted and has effect on usability perception ratings. Some other works demonstrated a reverse outcome, that is, a reverse of 'what is beautiful is usable', which implies that interfaces that are more usable can determine ahigher rating of aesthetic perceptions (Tuch et al., 2012 in Hart, 2014). Consequently, it appears that the assertion 'what is beautiful is usable' was only partly supported, because in some instances it can be explained as 'what is usable is beautiful' (Hart, 2014). There is however, one confounding problem with these research studies, and that is the manipulation of either aesthetics (via the altering of the interface designs), or the changing of the interfaces' usability feature, which of course can lead to issues and problems when making causal type interpretations, thus, it is evident that no distinct conclusions can be made. Some studies discovered that there are no associations between usability perceptions and perceived aesthetics, and that the two constructs were independent. Additional submissions were that the initial works (Tractinsky, 1997; Kurosu \& Kashimura, 1995) suffered from methodology-related problems because of the "improvised" designs that measured just the spatial layouts (without variations to styles, forms, or colors), thus making generalization to real/actual products challenging (Hassenzahl, 2004).

Furthermore, Hassenzahl (2001) adopted a social psychology viewpoint and noted that only usability and aesthetics cannot account for users' experiences and preferences with regard to their use of interactive products, because they neglected and overlooked the subjective hedonic nature of product 'appealingness', charm and pleasure. Hedonomics emerged as a set of non-task qualities and non-instrumental elements that determines the subjective judgments of product appealingness (Hassenzahl et al., 2000). Furthermore, Hassenzahl (2004) in a later work thatused the aesthetic quality ratings of MP3 player skins, examined the correlation between pragmatics perceptions (usability), and hedonic perceptions (stimulation and identification), together with two other evaluations constructs beauty (appeal) and goodness (value). While pragmatic qualities relate to the software product's capability to support ease-of-use, that is, "effective and efficient goal-- 
achievement", hedonic qualities refer to the "users' self", and relates to the products ability to offer pleasure through "stimulation by its challenging and novel character, or identification by communicating important personal value to relevant others" (Hassenzahl, 2004). Essentially, goodness relates to the general assessment of the value of a product, where as beauty is described as a predominantly affect-driven evaluative reaction to the visual Gestalt of a product, where visual judgments decisions can be made immediately, within very few seconds. The relationships between these facets are however intricate and complex. Hedonomics was discovered to be highly associated to beauty, where as goodness refers to "objective" pragmatics (that is, actual usability, instead of perceived usability), prompted by the mental effort involved in experiencing usability issues and task related performance. Despite the fact that perceived usability (that is, perceptions of pragmatic qualities) are vital drivers of goodness, none the less, no correlation was found between beauty and actual and perceived usability (Hassenzahl, 2004).

There is a distinction between evaluations and subjective perceptions and experiences. Though the latter let users to find out a product's novel characteristic, it is not essentially like an evaluation. Therefore, the perceived hedonics or pragmatics candrive users' positive evaluations, which however are not guaranteed. As Hassenzahl (2004) argued, perceptions of usability and goodness perceptions are influenced by experience, and are a such liable and open to variation, while perceptions of hedonics qualities and beauty perceptions stay stable in the course of time (Hassenzahl, 2004). Furthermore, context-ofuse and task typecan impact user perceptions of software product qualities, for instance, pragmatic qualities will be more vital when the user is in goal-mode (that is, concentrating on achieving a given goal), however, while in action-mode (that is, user is concentrating on actions), the hedonic qualities is more essential. As an example, if a user is surfing an e-commerce website to buy a particular product, then pragmatic qualities of the website is more significant, however if the same user is surfing the website to play a game, then hedonic qualities will take precedence and priority. The understanding of interactive digital experiences is actually a complex process. Conventional methods of assessing interactive digital artifacts stems from usability. They concentrated on user performance, ease of use, task success and ease of learning. However, usability alone does not fully account for highly subjective affective (emotional) experiences of users during product use in real life. This recognition led to the emergence of user experience (UX). any interactive system. Though the term UX is largely recognized in the HCI circles, its definition is vague, thus, making it challenging to design and evaluate interactive products and services on the basis of UX. 
Several theories have been suggested to help in the understanding of UX; however, there is yet no generally agreed UX model, framework or theory that has emerged (Hart, 2014). The significance of aesthetics in impacting and contributing to decisions and evaluative judgments about software product qualities draw much consideration in early UX studies, which however, was with conflicting results. This sparked a rise in studies to understand the complexities of user quality judgment (Hart, 2014). Prior UX studies concentrated on the multi-dimensional constructs of product pragmatics, affects, hedonics, ergonomics and aesthetics, and how these would impact user perception and judgment (Hart, 2014). These constructs can vary dependent on the context, environment, task, product, time and user background. Conversely, small consideration has been directed to the effect of interactive product attributes and designs qualities on UX. Hart (2014) found from her research that interactivity is a vital component in UX in both long and short-term usage. Hart (2014) also expanded the present process model of user quality judgment, via a set of studies to show the significance of interactivity and how users' initial or preliminary perceptions and judgments of a product's quality has the possibility of changing over time. Her studies ascertained the significance of interactivity in positively impacting on UX. The studies indicated that hedonic and affective perception ratings improved as aoutcome of interaction, signifying the strong influence of interaction, and indicating a lucid variations for websites that have enriched interactive elements and qualities, regardless of the presence of usability issues.

The role played by emotions and feelings is pivotal in UX. Emotion itself has been open for deliberation amongst scholars, this not with standing, a concluding definition for the concept has however, not yet been arrived at (Keltner et al., 2013). A number of studies are in agreement that affects can be assessed with reference to behavior, attitude, physiology, cognitive and conscious-experience (Mauss \& Robinson, 2009, as cited in Keltner et al., 2013). Furthermore, Russel (2003), in his work, made available a model for the explanation of emotional prototypes (Russell, 2003). Core affects lies at the heart of emotion. Russell considers core affect as the simply feeling of either good or bad, or energized or enervated (Russell, 2003). Core affect can be explained with reference to arousal (energized - enervated) and valence (pleasure - displeasure). For instance, jittery, is an affect which is considered as highly energized and of somewhat negative valence (that is, displeasure) and happiness is a relatively energized affect with high positive valence (that is, pleasure); (Kraus, 2017). As Russellposits, emotion is built from core affect, perceptions of affective quality, appraisal, attribution to object, emotional metaexperience, instrumental action, and emotion regulation (Russell, 2003). All of these constituents account for what Russell calls "a prototype of a specific emotion". Thus, the 
constituents impact on one another but however the impact is not in any given causal order (Russell, 2003). An emotional incident or occurrence is generated by an event which is perceived with reference to affect. Mean while, attribution is the extent to which the event is perceived as being accountable for the affect. Thus, by attributing an affect to an event, that event is becomes an object. Appraisal comprises the cognitive processes pertaining to the evaluation of the object with regard to "its future prospects, its relevance to one's goals, its causal antecedents" (Russell, 2003). A prototypical emotion in addition includes an action, for instance, "approach vs. with drawal" from the object set by "physiological and expressive changes" like "facial or vocal changes" (Russell, 2003). Emotion is additionally experienced consciously.

Emotions are complex constructs. Describing and measuring them is not a straight forward process. However, there are in existence, several questionnaires for the measurement of affect, like the Positive Affect - Negative Affect Schedule (PANAS) (Watson et al., 1988 in Hart, 2014) and the Self-Assessment Manikin (SAM) (Bradley \& Lang, 1994 in Olssen, 2012). Furthermore, feelings are also viewed as component of UX (Kraus, 2017). Feelings are described as gut feelings or intuitions that could be constituents of emotions but for which it is impossible to tell if they comprise all parts as stipulated in the Russel's model. Emotional reactions are a vital part of the experiential consequence in the usage of technology. Psychology investigates emotions from a scientific stand point by treating them as mental processes and behavior. Emotions basically comprise of: i) physical arousal: for example, perspiration; ii) expressive behaviors such as facial expressions or tone in speech, avoidance or approach, and; iii) conscious experience: for example, the feeling of joy, pride or anger, (Myers, 2004 in Olsson, 2012). Emotions are typically viewed as global, that is, not depending on the background or culture of the person in question. Kleinginna and Kleinginna (1981) in Olsson (2012) discovered more than 100 definitions for emotion and suggest a mutually consensus definition. However, emotion is a complex set of interactions involving objective and subjective factors, and is facilitated by neural-hormonal systems, which can: i) Lead to affective experiences, like the feelings of pleasure/displeasure or arousal; ii) Produce cognitive processes, like emotionally suitable appraisals, perceptive effects, and labeling processes; iii) Trigger extensive physiological adjustments to the arousing conditions; iv) Results to behavior that is usually, but not continually, expressive, and adaptive, and goal directed (Olsson, 2012).

Literature is replete with theorizations on the classifications of emotions. Several psychologists recognize several human responses as emotions, and to some extent 
different words are employed to denote related concepts. An extensively cited instance is the classification by Ekman and Friesen (1982) in Olsson (2012), comprising of six emotions: surprise, anger, joy, fear, sadness and disgust. Izard (1977) itemized similar terms with a few added in addition: surprise, anger, contempt,joy, distress, guilt, fear, interest, shame and disgust. Other suggested emotions are, for instance, anticipation, grief, courage, and pain. Also, some authors classify the emotions as structural frameworks that target at stipulating the variances in abstraction levels between different terms. For instance, Parrot (2001) in Olsson (2013) splits the anger-associated emotions into torment, irritation, rage, exasperation among others, and these were further divided intofrustration, aggravation, fury, agitation, annoyance etc. Desmet (2002) deliberates on emotional responses or reactions that results from the usage of products and finds 5 classes: i) amazement and surprise emotions such as astonishment and awe; ii) instrumental emotions, like satisfaction and disappointment; iii) aesthetic emotions associated with intrinsic and implicit pleasantness, for example, disgust; iv) social emotions such as admiration and in dignation; and v) interest emotions, like fascination and boredom (Olsson, 2012). Time and again, when emotions are talked about, the concepts of feelings and moods are stated also. Emotions are intuitive and are instinctual reactions or primitive responses to events that are external or to cognitive evaluative appraisal of events, and so are short enough to be assessed in seconds. Further, feelings are frequently considered as the conscious, mindful and aware experiences of emotional states, for example, the feeling of being short-, ill-, bad-tempered as a result of the emotional states of anger. On the other hand, a mood is a somewhat an emotional state that is long-lasting and varies from simple emotions as they are less intense, less specific, and less probable to be triggered/ activated by a given stimulus or event. Furthermore, moods as longer-term affective states, impact emotions through for example the strengthening or weakening of the valency of the emotion. Besides, personality traits like neuroticism or openness, impact both emotions and moods via predispositions to feel particular emotions. In summary, feelings, moods and emotions, are characteristic components of UX and play a vital part in the way users perceive their interactive environments. The affective or emotional element of an experience simply turns out to be central in interactions in which users feels, for example, surprise or frustration as a result of an interaction with a technological artifact. Emotions result to a methodology related challenges such as its short-term nature, subjectivity and dynamism, as well as the challenge of analyzing its data. For instance, Isomursu et al. (2007) presented a research in which 5 different self-report approaches for determining emotions were employed to elicit data about affective reactions to mobile apps. They found several challenges in each approach and on the basis of the lessons learned they 
suggested a basis for choosing the methodologies for different research purposes (Olsson, 2012).

Usability is usually considered as a "must-be quality", i.e., a basic quality in a design. It is a characteristic/requirement that is often taken for granted when included in a design yet results in dis satisfaction when not included. On the other hand, UX can be regarded as an "attractive quality". It is a sentimental and sensory oriented quality. It is a quality or requirement that offers satisfying experiences when incorporated into a product's design. However, it does not lead to dissatisfying experience when it is not incorporated (Kano et al., 1984). Equally, Zhang and Dran (2000) in Olsson (2012) considered the same contrasting duality but none the less used the expressions "hygiene factors" (extrinsic motivators) and "motivators" (intrinsic motivators). According to Olsson (2012), the qualities of experience can be crudely split into: i) 'hygiene factor-experiences'; and ii) 'stimulator experiences' (motivator experiences). Interestingly, usability is usually viewed as a 'hygiene factor': if it is missing, this perhaps leads to dissatisfying experiences (pain/frustration). Likewise, some of these experience qualities can be considered to have a parallel outcome, that is, the lack of it can lead to dissatisfying, discomforting or painful experiences, however if present in the design or the product, the user might not be aware of or even notice them. The user maynot perceive the experience of meaningfulness until it is lacking. In addition, negative experiences of information overflow, disgust, frustration, anxiety, or pain can be aroused as a result of bad product design with regard to relevance, personalization, or user control. Likewise, privacy is a desirable or an expectant experience which when well realized in a design, users may not even perceive or be bothered by or be conscious of it, however, when not realized or if badly realized, users may feel disturbed and this might strongly hinder other positive experiences or make users feel reluctant to use the product generally. Trust is another experience that might not be noticed when the product and/or its content are trustful or trustworthy however, contrary experiences such as disturbance or distrust may become some what enormous or strong when the content is not reliable or perhaps out-of-date. Equally, intuitiveness can also be perceived as a 'hygiene factor experience' with a 'contraexperience' of, for example, inconvenience. Generally, the 'hygiene factor experiences' or must-be quality experiences, can be somewhat implicit and unconscious to users, and therefore difficult to be identified as specific experiences (Olsson, 2012).

In addition, the variation also depends on the order in which the information is presented, positive or negative, signifying a priming or framing effect. Equally, experiences affected by the users'action-mode or goal-mode, that is, experiences of goal-orientated tasks, and users background,can impact on thepragmatic perception quality ratings (Van Schaik et 
al., 2012), and their priming/framing influence via different scenarios of experiential motivations (the experience is good or bad). In addition, Hassenzahl et al. (2010) explored user perceptions of need fulfillment in their study that elicited more than five hundred desirable interactive experiences on products. The findings showed lucid associations between positive affect and need fulfillment (for example, stimulating, competence, and relatedness). Perceived hedonic qualities were discovered to be high motivators (or attractive qualities) as a result of their capability to generate positive desirable experiences, where as perceived pragmatic qualities were perceived as hygiene qualities because it aided the fulfillment of needs; how ever they were not themselves a source of positive desirable experiences.

To deliberate on the practicality of these concepts' suitability and applicability, Chitturi et al. (2008) in Hart (2014) indicated that interactive products that meet or exceed pragmatic, ergonomic or utilitarian requirements/needs typically improve the user/customer satisfying experiences, while products that meet or surpass user hed onic requirements/ needs generally improve their delight and pleasurable experiences (Olsson, 2012). The concept of hedonic quality developed from consumer research, defines the positive facets of the perception of a product. It is connected to facets that go beyond the functional aspects, that is, product qualities that address the be-goals fulfillment (Hassenzahl, 2010 in Olsson, 2012). With regard to emotional influence, while pragmatic quality is some what related to the ability of an interactive product to attain or offer user satisfaction by the fulfillment ofuser needs and expectations, perceived hedonic qualities are however some what associated with the ability of an interactive product to offer pleasure, delight, happiness and psychological wellness and well-being (through the surpassing of user needs and expectations).

The facets of human behavior obtained from consumer studies specified and located affective and hedonomic experiences as dominant motivators-of-use. Similarly, design and ergonomic research studies on the other hand recognized that usability did not take into account the positive feelings of pleasure and happiness in product use which leads to emotional, affective and hedonic gains, that transcends usability. There have been a growing interest and popularity of affect in the design domain, as there has been for the motivational characteristics of fun, pleasure and enjoyment (Hart, 2014). 'Stimulator experiences' (that is, motivator, attractive or delightful experiences), appear not to lead to 'contra-experiences'. These experiences can stimulate, motivate, inspire, appeal to the senses of the user and consequently generate obvious instants that the user recognizes as a definite experience: for example, awareness, surprise, amazement, creativity, playfulness, inspiration, captivation, or motivation. Meanwhile, when a stimulating experience 
(attractive quality experience) is lacking, such experience would nonetheless not be negatively perceived. Rather, the user might just feel normal, or perhaps dull at most or conventional. Hygiene (must-be) qualities are usually the precursor for motivator experiences to be realized in a design. Usually a usable, effective and efficient performance on a productgenerates experiences of overall pleasure, happiness, and delight and enables the evocation and recall of motivator experiences. Lastly, the experiences of efficiency and empowerment which can be considered as rather more general associates and account for several other positive and desirable experiences (Olsson, 2012).

Generally, delightful experiences have a somewhat great variety of desirable experiences. Majority of the research accounts provided report that cognitive, pragmatic and instrumental aspects of efficiency, empowerment and awareness are linked to a user's immediate environments. Experiences which are emotionally concentrated, such as fascination, surpriseand general pleasure are also emphasized in a number of research accounts. Other experiences forms, like social experiences and immersion are obviously less recurrent and common. On the other hand, the explanations about unsatisfying experiences concentrate on different levels of instrumental dissatisfying experiences and the emotions of frustration that are associated with them (Olsson, 2012). According to Olsson (2012), the interaction and interface that are specific to interactive systems contribute typically to the experiences of immersion and awareness. Furthermore, the charm or appeal of novelty in the interaction symbolism or metaphor, together with the novel functions in the design, typically elucidates the affective experiences of surprise and fascination (Olsson, 2012). The dis satisfying and desirable experiences come mostly from hardware deficiencies, insufficient user performance, bad usability, unmet instrumental expectations, or inappropriate content. As a result of the critical, but typically simple resolvable usability issues and remediable functionalities, the added experiential issues such as lack of inspiration or privacy would not be given emphasis to. With regard to disappointment and other frustrating experiences, it also appears that the users' subjective explanations about their experiences easily became powerfully slanted with emotional slurs and spices to the extents that other experiential constituents are given less importance. Generally, the range of the experiences that are dissatisfying is narrower than that of experiences that are satisfying, possibly as a result of the stress on overall evaluated dissatisfactions and disappointments (Olsson, 2012).

As technology market is pervaded immensely with lots of varied services, it is pertinently needful to differentiate these services by positive experience. Wow is obviously a positive experience and a notable design goal that binds users firmly to a product during and after interaction (Väänänen-Vainio-Mattila et al., 2011). On the basis of Hudson and 
Viswanadha (2009) in Rezaei (2015) work, a wow product is such that not only meet user's needs but also i) meets unexpected needs and ii) stimulates a higher sense of control over the interacting product. As Väänänen-Vainio-Mattila et al., (2011) stressed, it is a pointer to users being surprised as an indication that their needs or expectations have been transcended or surpassed as observed by Desmet et al. (2005). None the less, as wow is surprise inducing, it is reasonable to note that a product comprising wow may not always retain the quality over time. For it to remain, the product must undergo constant innovative enhancements (Desmet et al., 2005). However, Schauer (2008) in Rezaei (2015) stresses that a product must stimulate a long-term wow experience in order to retain users or customers and to make and keepthem loyal. Schauer suggested some overall guide to generate and sustain wow experiences over time. These as follows: i) reaching out to broad spectrum of customers unfulfilled needs or ii) producing a wide range of wow instants that can emerge and be sustained via a user's platform of touch points over the long period of time. Hudson and Viswanadha (2009) proposed that to attain a wow experience, the designer should make forms of interaction novel, invite user to play with the interface and provide suitable feedback to users. Playfulness may contradict or complement usability in some situations, however, for novelty in interactions, the designer may not have to develop fresh interaction techniques, but apply existing ones in improved or some what unexpected manners. Väänänen-Vainio-Mattila et al. (2011) recommended that with good aesthetic experience and adequate usability together with continual feeling of trust, it is possible to achieve wow experiences in sustained product use. The authors also itemized the features of wow experiences as comprising the following: i) Wow is positive, surprising, and is usually an emotional experience; ii) though wow is sudden, however, it may also be in product use over time, that is, in long-term usage, when the product remains secured and pleasant, iii) Wow is a "peak experience", that is very memorable, personal, meaningful and subjective, iv) Wow is a pleasurable affective response that take place via product interaction that transcends or surpasses the user's desired expectations (Rezaei, 2015).

Akin to other forms of experiences, wow or hedonic experience is also associated to the qualities of the interactive product, usage context and users' characteristics. Affective attributes of the product that result in a user's wow experiences are revealed in prior studies (Rezaei, 2015). For example, Steen et al. (2003) showed that the following elements lead to the experience of wow: sensorial experience, nostalgia, fantasy, amazement, beauty, exclusivity, budget, surprise, comfort, connectedness, mastery, own world, competition, care, and inspiration. Prior studies reveal that playfulness can also account to the formation of positive experiences when incorporated into product design 
(Rezaei, 2015). A playful experience model is a design framework which can be used to inspire pleasurable designs for some particular kinds of playful experiences such as challenge, competition, fantasy, thrill, and nurture (Rezaei, 2015). This should form the basis for the measurement of the realization of such user expectations and needs in the context of interactive systems (Rezaei, 2015), as comparable, or at least a subgroup of the basic user requirements and needs can be presumed to be in wow experience (VäänänenVainio-Mattila et al., 2011). One of Väänänen-Vainio-Mattila's et al. (2011) design guidelines for wow experience stresses that to design for users' needs that are not met yet, examine overall their present situations and unearth the needs that are yet unmet, and then proffer innovative solutions for them. Rezaei (2015) used this guideline. This was collaborated by Voida et al. (2013). Väänänen-Vainio-Mattila et al. (2011) also suggested a good aesthetics and better usability for effective wow design. It implies that a mere usability is inadequate for desirable wow experiences, and interactive systems must transcend or exceed usability by providing some novel and innovative features ininteractive products. According to Rezaei (2015), one important aspect that designers must examine tactfully is the balancing of security with wow experiences because the neglect of security may bring about suspicious feelings and lead to other security concerns in the mind of the user (Väänänen-Vainio-Mattila et al., 2011). That is, designers must not target at only improving wow experience at the cost of diminishing considerations for system security and users concerns fortrust (Rezaei, 2015).

There is a widely held notion that user satisfying experiences is a determinant of business and destination performance that usually bonds satisfying experiences to returns that is built on higher gains associated with greater overall demand, customer intentions to return, sales, and other indicators pointing towards business accomplishments and success (Mathe-Soulek et al., 2015). Where as the successful provision of satisfying positive experiences has been revealed to lead to: i) long-term impacts on competiveness; ii) revisit intentions; iii) recommendations to others along with other sorts of positive promotions or word-of-mouth advertisements, a number of theories recommend various approaches or links to evaluate user satisfying experiences. Furthermore, expectancy theory has long been a wide spread notion that demonstrates correlations between user satisfaction experiences, actual performance outcomes and prior user expectations. Though there are disagreements as to how the constituents of the framework of expectation-disconfirmation interplay, however, users/consumers have a priori expectations of product features/qualities that influence their post purchase or after use satisfying experiences which they hinge on if actual performance surpasses, satisfy or does not satisfy their apriori expectations. 
Furthermore, previous works that test the influence of category assessment, quality attributes, and the effect of product performance on user positive satisfying experiences are scare. In addition, studies looking into the correlations among quality characteristics and satisfying experiences have had some in adequacies. Where as the Mathe-Soulek et al. (2015) work delivered a number of enhancements over previous studies to ascertain meaningful quality characteristic-correlations, it had none the less some weaknesses. A key weakness was the ignoring of the moderating effects in the quality attributesatisfaction correlation. While usability and other ergonomic qualities emphasizes the removal of pain and the making of products and systems comfortable for/in use (ergonomics), UX emphasizes the provision of pleasurable and desirable qualities for the delight of the users (hedonomics). These two broad viewpoints entail the way interactive products are designed and evaluated for use. Researchers are interested on how to minimize users' pain (and maximize their comfort) and how to promote their happiness, joy, fun, leisure, pleasure, wellness, and wellbeing in interaction in products' designs and evaluation. This necessitates for the formulation of frameworks to will facilitate the ergonomics and hedonomics of interactive products. There are some frameworks that are available in other domains and contexts like management, marketing etc.

In the personnel management domain, Herzberg et al. (1959) presented a 2-factor framework, that is, the hygiene-motivator framework. In this model, the critical incident protocol was employed in a job satisfaction context to assess the effect of hygiene and motivator variables on workers' experience. Motivators or stimulators are factors that lead to positive experience and sustain motivation for continuous enhancement of experience of the workers. Hygienes, on the other hand, are factors that are not related to a given job but rather with the job associated conditions (job environment). Motivators are attributes associated with the content of a job that stimulate the person on the jobwhile hygienes are job context attributes (the job environment) (Zhang \& Dran, 2000) in Olsson (2012). The absence of hygiene factors increases pain and lowers comfort while the presence of motivator factors enhances happiness, joy and pleasure. Furthermore, Swan and Combs (1976) provided a further backing for the Herzberg et al.'s (1959) hygiene- motivate or framework. They offered a corresponding relationship between hygienes and motivators with instrumental and expressive qualities. Where as expressive attributes are the psychological facets of an interactive product (that deals with the improvement of the wellbeing and functioning of the users of a product), instrumental attributes are the physiological, that is the physical facets of an interactive product that pertain to the easeof-use and functioning of the product itself. 
Further, in the consumer and marketing research field, Oliver (1997) conceptualized a three-factor framework that postulates the correlation between users' need realization and their satisfaction with respect to the factors: bivalent satisfiers, monovalent satisfiers, and monovalent dissatisfiers. While the monovalent dissatisfier attribute offers the greatest cause of negative experience with a product, monovalent satisfiers offer the greatest source positive experience. However, bivalent satisfiers influence both positive and negative experiences. In addition, while bivalent satisfiers impact positive experience linearly, decrease in monovalent satisfiers does not lead to a negative experience with a product, and increase in the monovalent dissatisfier attribute does not lead in positive product experience. As Oliver (1997) opined, there may be no clarity in the line of difference between positive and negative product experiences, nonetheless, the duality can be viewed as a 'indifference zone'. He however stressed that the monovalent dissatisfiers and satisfiers account for product experience modestly. Similarly, Cadotte and Turgeon (1988) introduced a four-factor framework with dissatisfiers, criticals, satisfiers, and neutrals as supposed spread of performance perceptions of product qualities. While the first three quality factors are experience aware, stimulating and inducing, the last quality factor is experience agnostic. The satisfier attribute is quality attribute that elicits positive experience when realized but their non realization does cause negative experience. They fulfil or realize the intrinsic requirements/needs of users. The dissatisfier attribute on the other hand is quality attribute that can lead to negative experience if absent in the design of a product how ever its realization or presence in the product does not improve positive experience. These quality attributes fulfil the extrinsic requirements and needs of users. Users' extrinsic needs are both physiological, functional, cognitive, instrumental and pragmatic. Criticals are quality attributes that influent both negative and positive product experiences (Cadotte\& Turgeon, 1988). These quality attributes may be most important elements to hold constant as they cause both positive and negative effects on experience. Neutrals on the other hand are experience agnostic attributes. Their presence or absence in a product neither create negative nor positive responses or reaction from the user (Cadotte \& Turgeon, 1988).

Dissatisfiers appear to have a higher influence on experience, but the impact of criticals on experience appear to be greater than both the dissatisfier and satisfier attributes because this critical quality factor (criticals) indicates duality of experience effects of an interactive product. In the course of time, a product quality evolution takes place and satisfier attributes are changes to criticals while criticals ultimately are transformed to dissatisfiers over time (employing the terminology of Kano et al. (1984), the evolution is occurs from attractive product quality to the one-dimensional attribute and over time to 
must-be quality attributes) as a result of product continuous usage and subsequent user product familiarization, market competition, change in user tastes, technology advancements, change in organizational policies, changes in the needs, requirements, and expectations of customers/users, and users' adaptation/acquaintances to the product. The evolutionary circle from satisfier to critical and then to dissatisfier quality factors may as well happen when there is a change in the user's attachment with the product's company. This infers that while users who are new to a product may view certain quality attributes in the product assatisfier quality, already existing and long standing but loyal users may perceive these same quality attributes as expected and basic factors and hence, the quality attributes become dissatisfier qualities. The survival, penetration, success, sustenance, and maintenance of the product on the long run relies not just the successful realization of users' needs or expectations (requirements) or even surpassing them but it also hinges on the close supervising of these expectations/needs (requirements) by the sales and/or product manager.

Further more, Kano et al. (1984) presented a five-factor framework from a mechanical engineering view point. The framework was derived/ adapted from the Herzberg et al.'s (1959) hygiene-motivator framework. Their work conceptualized 5 quality attributes that influences experience. These factors include, inter alia: must-be, one-dimensional, attractive, in different, and inverse quality attributes. Must-be quality attributes/ design factors are those qualities that users expect in a product as basic and fundamental qualities. Hence, because these qualities are usually expected, users' usually take them for granted when they are realized (that is, met or present) in a product, none the less the fulfillment/incorporation of these qualities into the design of the product lead to negative experiences (responses) when not met or absent in a product. The presence of these factors do not improve experience (does not lead to positive responses), however, their absence leads to poor experiences (negative reactions like pain, disgust, frustrations, anger). One-dimensional quality attributes or design factors are those product quality attributes that lead to positive experiences (pleasure) when met or present in a product and result in negative or poor experience (pain) when they are unmet or absent in the product's design. Attractive quality attributes (or design factors) are the product quality attributes that increase users' positive experience (pleasurable response) when met or present in the product's design. They are acceptable even when they are unmet or absent in the product (that is, their absence do not cause any pain). In different quality attributes are the quality attributes that result in neither positive (pleasurable) nor negative (painful) experiences. Reverse quality attributes are the quality attributes that result in positive experience when unmet or absent in a product and in negative experience when met or 
present in a product. That is essentially, users/customers are happy when these attributes are not there and sad when they are there. This implies that these quality attributes should not be in the product's design.

Kano's model (1984) of attractive quality that explains the types of product attributes and association existing amid product overall satisfaction and quality performance has been utilized as a foundation theory however; its several in adequacies has been critiqued. Furthermore, a lot of research and models have braced the view of a 3-factor framework for modeling product quality attributes. In Rust et al. (1996), a 3-factor model comprising dissatisfiers (expected/fundamental factors), satisfiers, and delighters was proposed. Both the satisfier and delighter factors are unexpected factors. Following Rust et al. (1996) scheme, Brechan (2006) posits that a hierarchy exists in the ordering of the three quality types. The order is as follows:1) primary (basic or the dissatisfier attributes), 2) secondary (satisfier attributes) and 3) tertiary (delight or sensational attributes). This idea about the hierarchy of product quality attributes is anchored on the following arguments and stand point: i) the primary/fundamental (basic) qualities (that is, dissatisfiers) meets instrumental/functional (pragmatic/utilitarian) needs (basic quality attributes are must-bes, Kano et al. (1984)); ii) that secondary (expressive) factors (that is, one-dimensional) fulfill/meets non-essential but anticipated hedonic needs (these quality attributes are also performance, expressive and one-dimensional in nature, and as ancillaries, they provide added and enriched experiences); and iii) that tertiary factors (delighters or wow, sensational quality attributes) fulfill/meets experiential unexpected hedonic needs (Brechan, 2006). Tertiary factors are also attractive quality attributes (Kano et al. (1984) and very important elements in the design of interactive digital products). Interestingly, this three factor concept breaks down experience into three categories, namely, 1) fundamental experience (aroused by fundamental physiological factors), 2) ancillary experience (that is beyond the basic experience but emanating from the inclusion of ancillary factors in the design of the system), and sensational experience (caused by sensational/excitement/wow ('surprise') factors). Following these concepts, its best to model experiencein three categories: fundamentals (essential, functional and instrumental design/product features that dissatisfy users when not present), ancillaries (anticipated desired hedonic design/product features that satisfy users) and sensationals (unanticipated hedonic design/product features that delight already satisfied users)

There are several frameworks for the understanding for the dynamics of pain and pleasure factors in interactive product design. However, from this review, these frameworks as good as they are, were not specifically developed for the user experience (UX) domain and thus were not designed to capture the design concerns of user experience designers. 
The frameworks do not address the characteristic concern of UX. Designers and evaluators in the UX field are particularly interested in a custom (domain specific) framework that supports the design of interactive systems. In the light of this, considering the peculiarities of HCI and UX in particular, this study proposes a product pain-pleasure framework for the design of interactive products in the usability and user experience domains.

\section{Methodology}

In this study, a literature review method was used to examine the ergonomic and hedonomic frameworks for the design of experience. As a literature review, necessary related literature materials were downloaded and synthesized. Following this was the extraction of relevant information for the formulation of a pain-pleasure design framework. The protocol observed is as follows: i) download articles associated with the design of pain-pleasure frameworks; ii) synthesize and analyze the articles; iii) extract required information for the formulation a product pain-pleasure framework for the design of interactive systems; iv) propose the product pain-pleasure design framework. Figure 1 illustrates the framework used in this study.

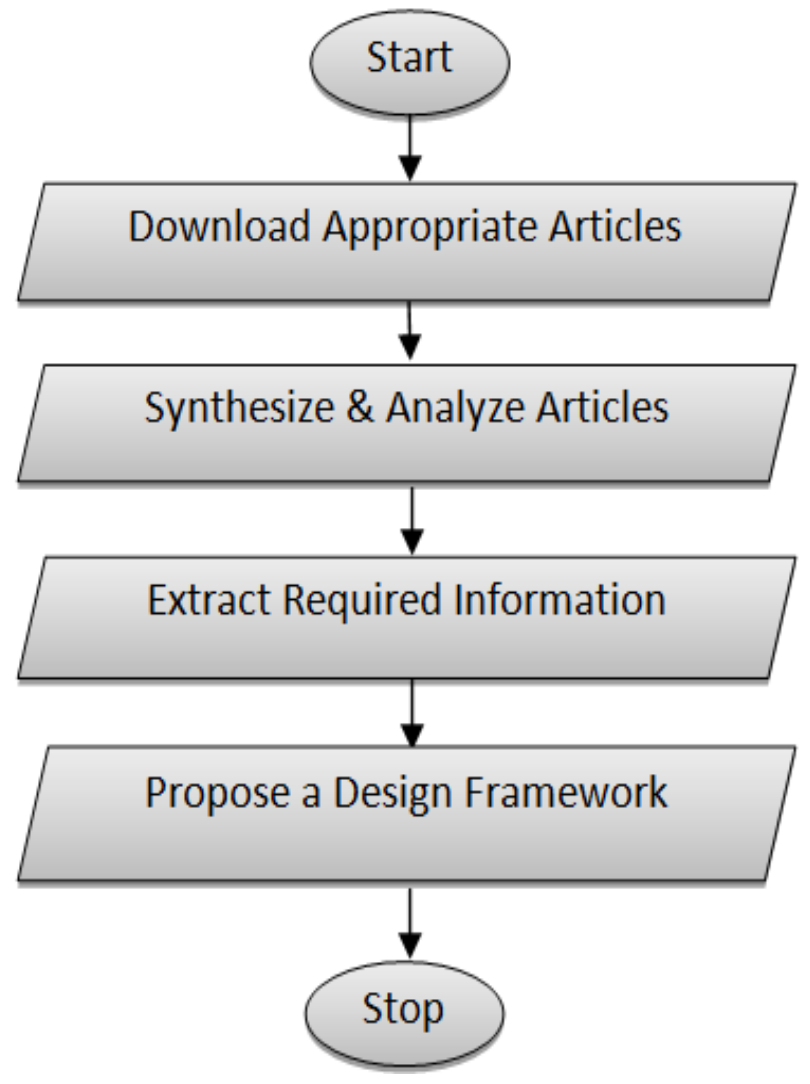

Figure 1 Research Protocol 


\section{Results}

This study delved into extant literature to examine the frameworks for the design of products that minimizes users' pain and maximizes their pleasure of use. The study found that most available related frameworks were from other domains such as management, consumer and marketing, and mechanical engineering.

Secondly, the emphasis of most of the frameworks was skewed primarily to customer satisfaction and dissatisfaction, an applicable but minute aspect of user experience. User experience is a broader field that encompasses affective, emotional, and hedonic aspects of product use among others.

Table 1 Quality Factors for the Design and Evaluation of Experience

\begin{tabular}{|c|c|c|c|c|c|c|}
\hline \multirow{3}{*}{$\begin{array}{l}\text { Model } \\
\text { Type } \\
\text { 2-Factor }\end{array}$} & \multirow{2}{*}{$\begin{array}{l}\text { Sources } \\
\text { Herzberg et } \\
\text { al. (1959) }\end{array}$} & \multicolumn{5}{|l|}{ Taxonomy } \\
\hline & & $\begin{array}{l}\text { Hygiene } \\
\text { Factors }\end{array}$ & $\begin{array}{l}\text { Motivator } \\
\text { Factors }\end{array}$ & - & - & - \\
\hline & $\begin{array}{l}\text { Swan \& } \\
\text { Combs } \\
(1976)\end{array}$ & $\begin{array}{l}\text { Instrumental } \\
\text { Factors }\end{array}$ & $\begin{array}{l}\text { Expressive } \\
\text { Factors }\end{array}$ & - & - & - \\
\hline \multirow[t]{2}{*}{ 3-Factor } & $\begin{array}{l}\text { Rust, Zahorik } \\
\& \\
\text { Keiningham } \\
(1996)\end{array}$ & Dissatisfiers & Satisfiers & Delighters & - & - \\
\hline & $\begin{array}{l}\text { Brechan } \\
(2006)\end{array}$ & Primary & Secondary & Tertiary & - & - \\
\hline \multirow[t]{2}{*}{ 4-Factor } & Oliver (1997) & $\begin{array}{l}\text { Monovalent } \\
\text { Dissatisfiers }\end{array}$ & $\begin{array}{l}\text { Bivalent } \\
\text { Satisfiers }\end{array}$ & $\begin{array}{l}\text { Monovalent } \\
\text { Satisfiers }\end{array}$ & $\begin{array}{l}\text { Null } \\
\text { Relationshi } \\
\text { ps }\end{array}$ & - \\
\hline & $\begin{array}{ll}\text { Cadotte } \quad \& \\
\text { Turgeon } \\
(1988)\end{array}$ & Dissatisfiers & Criticals & Satisfiers & Neutrals & - \\
\hline 5-Factor & $\begin{array}{l}\text { Kano et al. } \\
(1984)\end{array}$ & Must-be & $\begin{array}{l}\text { One- } \\
\text { dimension } \\
\text { al }\end{array}$ & Attractive & In different & $\begin{array}{l}\text { Inve } \\
\text { rse }\end{array}$ \\
\hline 3-Factor & $\begin{array}{l}\text { Current } \\
\text { Study }\end{array}$ & Pain Factors & $\begin{array}{l}\text { Linear } \\
\text { Factors }\end{array}$ & $\begin{array}{l}\text { Pleasure } \\
\text { Factors }\end{array}$ & - & - \\
\hline
\end{tabular}


Webology, Volume 18, Special Issue on Artificial Intelligence in Cloud Computing January, 2021

Table 2 depicts some of the qualities of the proposed Product Pain-Pleasure framework as follows:

Table 2 Some Qualities of the Product Pain-Pleasure Framework

\begin{tabular}{|c|c|c|}
\hline Pain Factors & Linear Factors & Pleasure Factors \\
\hline $\begin{array}{c}\text { Behavioral/Performance/ } \\
\text { Functionality }\end{array}$ & Visceral (Impressive, Engagements, Immersive, \\
Reflective, Flow)
\end{tabular}

The product pain-pleasure (PPP) framework is a hierarchical framework that consists of three factors in the order: pain, linear and pleasure factors (Figure 2). Pain factors are monovalent ergonomic and influence only users' pains, linear factors are bivalent hedonic and influence both users' pains and pleasures and therefore very critical in a product; while pleasure factors are monovalent hedonic and they influence only users' pleasures (See Table 2 for details). These factors are illustrated as follows:

i. $\quad$ Pain factors $(\mathrm{PnF})$ : Absence $=\uparrow$ Pain \& Presence $=0$ Pleasure

ii. Linear factors (LrF): Absence $=\uparrow$ Pain $\&$ Presence $=\uparrow$ Pleasure

iii. Pleasure factors (PsF): Absence $=0$ Pain $\&$ Presence $=\uparrow$ Pleasure

The pain factors are basic and fundamental design factors that when incorporated into interactive product design does not necessarily enhance users' pleasure however there none inclusion into the design will cause or lead to users' pain and discomfort. Users' usually expect to see such qualities in the product. So, their presence is taken for granted but since these are what they expected, their absence in the product design will cause 
disgust, frustration, and pain to users. Designers should ensure that these factors are incorporated in product design as their absence affects the performance, comfort and acceptance of the product in use. Their inclusion is a must for the success, maintenance, existence and survival of the product. Factors in this category are physiological, functional, pragmatic, instrumental, utilitarian and ergonomic in nature. Examples of such qualities are functionality, usability, usefulness, security, safety, privacy, intuitiveness, trust, efficiency, effectiveness, empowerment, awareness, reliability etc. These qualities lead to users' pragmatic satisfaction through the fulfillment of their expectations.

The second factors are linear factors. These design factors as the name implies has a linear relationship. While their presence in the design leads to pleasure, their absence from the design leads to pain. These factors are very critical to the success, survival and market penetration of the product since the presence or absence of the factors has critical design implications and either of them affects the experience of users. These qualities are doubly important as either ways they affect both the ergonomic and hedonic needs and experience of users. These qualities like the pain factors also impact on the product's performance in terms of usage success and market penetrability. Without these factors, the sustainability and survival of the product is at risk. Qualities in this category share both ergonomic and hedodonic characteristics and include the following: sociability, aesthetics, ubiquity, interactivity, ludicity and engageability etc. These qualities produce high product loyalty in users.

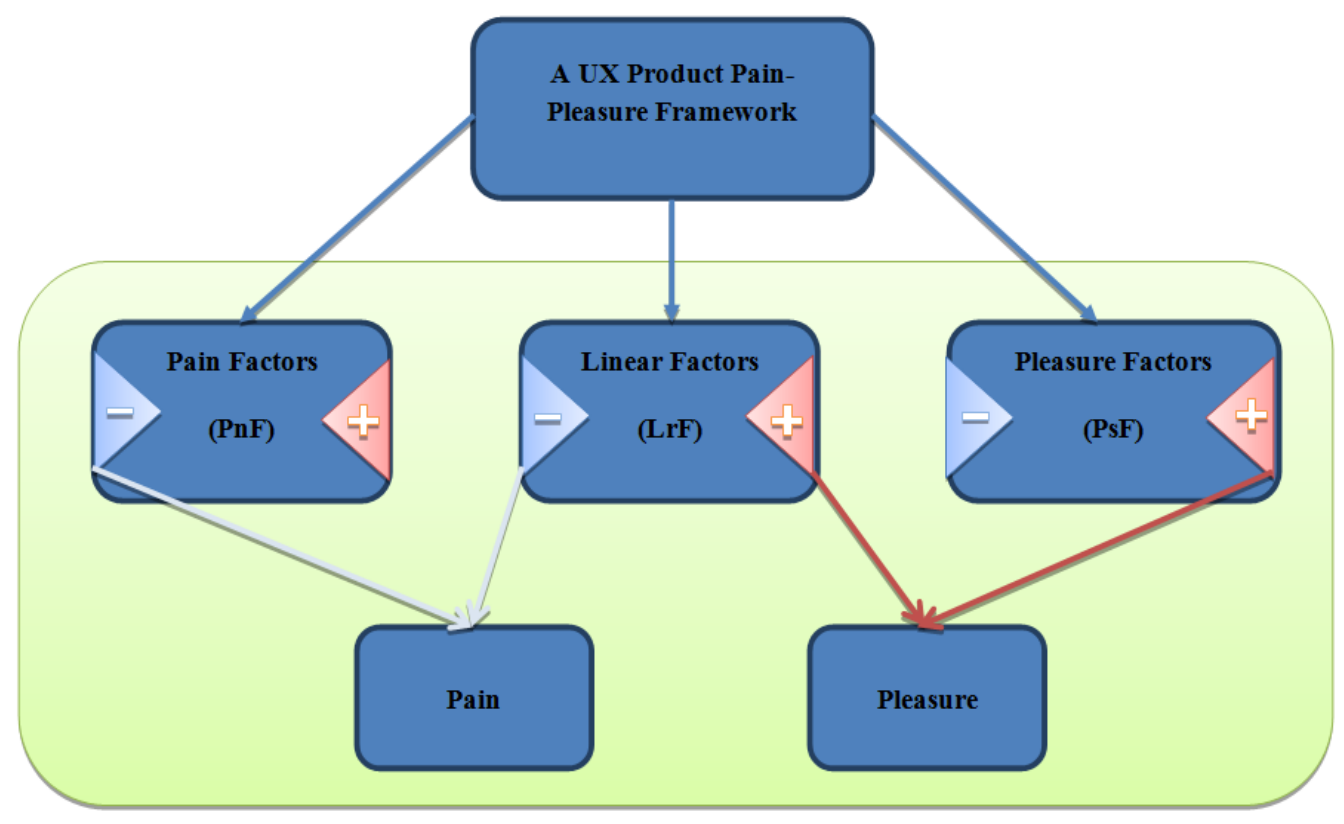

Figure 2 A UX Product Pain-Pleasure Framework 
The third factors are transcendental pleasure factors. The inclusion of these qualities into the design of the interactive product promotes or stimulates users' pleasure but their noninclusion does not in any way cause them pain. These factors are pleasure inducing qualities. The qualities differentiate products (that is, make them distinct) and give them an outstanding competitive advantage, making them to uniquely stand out among other products in the market. These factors are very attractive (appealing and charming) to users and give sumptuous delight, fun, leisure, and amusement to their users. They improve users' growth, health, self-functioning and wellbeing. Products with these qualities excel exceptionally in use and in the market as they are the desire and dream of consumers. They lead to high word of mouth promotion and exceptional product evangelism. They produce very high return on investment. The qualities in this category include: selfesteem, pride, visual aesthetics and attractiveness, immersive user engagement, surprise, amazement, playfulness, captivation, inspiration, motivation, inspiration, creativity, novelty, fascination, immersion, evocation, individuation, pleasure, fun, happiness and transcendent joy etc. Pleasure factors achieve hedonic pleasure and wellbeing of users by exceeding their expectations. They lead to users' personal growth, self-functioning, selffulfillment and self-actualization. Designers must ensure to incorporate these incredible characteristics in interactive product design as these catchy, charming and unexpected qualities create surprise in users and very much delight and attract them to a product.

\section{Conclusion}

In this study, a literature review methodology was used to assess previous literature concerning product pain-pleasure frameworks for the design of interactive products. The study discovered that several such frameworks exit but are mostly found in other domains other than usability and user experience. In the domains where they are found, the emphasis were on satisfaction and dissatisfaction criteria which do not encompass the broader perspectives of user experience that include hedonic, affective, aesthetics and other hedonomic aspects. This draws attention for a domain customized framework that captures the suiting concerns of designers of the user experience of interactive digital systems. The proposed framework is adapted from the frameworks elicited from literature but tailored to usability and use experience. It is a 3-factor hierarchical framework comprising pain, linear and pleasure factors with their respective theoretical peculiarities. The study proposes this framework to improve the experience of users of the interactive systems. 


\section{References}

Alharbi, M.S. (2016). User experience dimensions, aspects and measures: systematic literature review. Masters Thesis, Prince Sultan University.

Brechan, I. (2006). The different effect of primary and secondary product attributes on customer satisfaction. Journal of Economic Psychology, 27(3), 441-458.

Cadotte, E.R., \& Turgeon, N. (1988). Dissatisfiers and satisfiers: suggestions from customer complaints and compliments. Journal of Consumer Satisfaction, Dissatisfaction Complaining Behavior, 1(1), 74-79.

Carroll, J.M., \& Thomas, J.C. (1988). Fun. SIGCHI Bulletin, 19(3), 21-24.

Desmet, P.M.A. (2002). Designing Emotions. Doctoral dissertation, The Netherlands: Delft University of Technology.

Desmet, P.M.A., Porcelijn, R., \& Van Dijk, M.B. (2005). How to Design Wow?: Introducing a layered-emotional approach. In Proceedings of The International Conference on Designing Pleasurable Products and Interfaces, 24-27.

Hart, J. (2014). Investigating user experience and user engagement for design. Doctoral Dissertation, Manchester University.

Hassenzahl, M. (2001). The effect of perceived hedonic quality on product appealingness. International Journal of Human-Computer Interaction, 13(4), 481-499.

Hassenzahl, M. (2004). The interplay of beauty, goodness, and usability in interactive products. Human - Comp. Interaction, 19(4), 319-349.

Hassenzahl, M. (2010). Experience design: technology for all the right reasons. Synthesis Lectures on Human-Centered Informatics, 3(1), 1-95.

Herzberg, F., Snyderman, B.B., \& Mausner, B. (1959). The motivation to work, $2^{\text {nd }}$ Edtion. New York: John Wiley and Sons.

Isomursu, M., Tähti, M., Väinämö, S., \& Kuutti, K. (2007). Experimental evaluation of five methods for collecting emotions in field settings with mobile applications. International Journal of Human-Computer Studies, 65, 404-418.

Izard, C.E. (1977). Human emotions. Plenum Press, 495.

Kano, N., Seraku, N., Takahashi, F., \& Tsuji, S. (1984). Attractive quality and must-be quality. Hinshitsu (Journal of Japanese Society of Quality Control), 14, 39-48.

Keltner, D., Oatley, K., \& Jenkins, J.M. (2013). Under-standing emotions. 3rd ed. John Wiley \& Sons.

Kraus, L. (2017). User experience with mobile security and privacy mechanisms. Doctoral Dissertation, Technischen Universität Berlin.

Kurosu, M., \& Kashimura, K. (1995). Apparent usability vs. inherent usability: experimental analysis on the determinants of the apparent usability. In Conference on companion on Human factors in computing systems, 292-293.

Law, E.L., Roto, V., Hassenzahl, M., Vermeeren, A., \& Kort, J. (2009). Understanding, scoping and defining user experience: a survey approach. In Proceedings of the SIGCHIConference on Human Factors in Computing Systems (CHI), 719-728. 
Malone, T.W. (1981). Toward a Theory of Intrinsically Motivating Instruction. Cognitive. Science, 5(4), 333-369.

Mathe-Soulek, K., Slevitch, I., \& Dallinger, I. (2015). Applying mixed methods to identify what drives quick service restaurant's customer satisfaction at the unit-level. International Journal of Hospitality Management, 50, 46-54.

Meiners, M.L., \& Sheposh, J.P. (1977). Beauty or brains: Which image for your mate? Personality and Social Psychology Bulletin, 3(2), 262-265.

Nielsen, J. (1993). Usability Engineering. Academic Press.

Nielsen, J. (1994). Usability inspection methods. In Conference companion on Human factors in computing systems, 413-414.

Norman, D.A. (2002). The design of everyday things. Basic Books, 257.

Oliver, R. (1997). Satisfaction: a behavioral perspective on the consumer. McGraw-Hill Series in Marketing, New York, USA: McGraw-Hill.

Olsson, T. (2012). User expectations and experiences of mobile augmented reality services. Tampere University of Technology, Tampere.

Partala, T., \& Kallinen, A. (2012). Understanding the most satisfying and unsatisfying user experiences: Emotions, psychological needs, and context. Interacting with computers, 24(1), 25-34.

Porteous, J.D. (1996). Environmental Aesthetics: Ideas, Politics and Planning. Routledge.

Rezaei, P.P. (2015). User experience studies of personal cloud storage services. Masters Thesis, Tampere University of Technology, Tampere.

Pereira, R., Buchdid, S.B., Miranda, L.C., \& Baranauskas, M.C.C. (2013). Paying Attention to Values and Culture: An Artifact to Support the Evaluation of Interactive Systems. International Journal for Infonomics (IJI), 1(1), 792-801.

Russell, J.A. (2003). Core affect and the psychological construction of emotion. Psychological review, 110(1), 145-172.

Rusk, R.T., Zahorik, A.J., \& Keiningham, T.L. (1996). Service Marketing. New York: Harper Collins.

Samardzija, A.C. (2016). Measuring the success of the interactive mobile information system at the individual level of use. Doctoral Thesis, University of Zagred.

Shackel, B., \& Richardson, S.J. (Eds.). (1991). Human Factors for Informatics Usability. Cambridge University Press.

Sheldon, K.M., Elliot, A.J., Kim, Y., \& Kasser, T. (2001). What is satisfying about satisfying events? Testing 10 candidate psychological needs. Journal of personality and social psychology, 80(2), 325.

Steen, M., De Koning, N., \& Hoyng, L.L.M.L. (2003). The 'wow' experience -- Conceptual model and tools for creating and measuring the emotional added value of ICT. COST269 conference Good Bad Irrelevant, Helsinki.

Swan, J.E., \& Combs, L.J. (1976). Product performance and consumer satisfaction: a new concept. Journal of Marketing, 40(2), 25-33. 
Tractinsky, N. (1997). Aesthetics and apparent usability: empirically assessingcultural and methodological issues. In Proceedings of the ACM SIGCHI Conference on Human factors incomputing systems, 115-122.

Väänänen-Vainio-Mattila, K., Palviainen, J., Pakarinen, S., Lagerstam, E., \& Kangas, E. (2011). User perceptions of wow experiences and design implications for Cloud services. In Proceedings of the Conference on Designing Pleasurable Products and Interfaces.

Van Schaik, P., Hassenzahl, M., \& Ling, J. (2012). User-experience from an inference perspective. In ACM Transactions on Computer-Human Interaction (TOCHI), 19, 11. 